\title{
Prática Teatral em um Hospital de Custódia: à luz dos olhos velados
}

Bruna Traversaro ${ }^{1}$

Fabiana Lazzari de Oliveira²

Recebido em: 11/10/2019

Aprovado em: 01/04/2020

DOI: $10.5965 / 2358092521232020305$

1 Graduanda em Licenciatura em Teatro na Universidade do Estado de Santa Catarina (UDESC). E-mail: brunatraversaro@gmail.com

2 Doutora em Teatro pela Universidade do Estado de Santa Catarina (UDESC). Professora da Universidade de Brasília (UnB). E-mail: fabianalazzari@gmail.com 


\section{RESUMO}

O presente relato expõe uma experiência de estágio realizado no Hospital de Custódia e Tratamento Psiquiátrico (HCTP) de Florianópolis, no primeiro semestre de 2019. A prática esteve associada à disciplina de Estágio Curricular Supervisionado Teatro na Comunidade I, do curso de Licenciatura em Teatro do Centro de Artes (CEART) da Universidade do Estado de Santa Catarina (UDESC) e visa propor experiências além da rotina hospitalar/carcerária, cooperando com a integração entre os pacientes e com a futura reintegração social.

Palavras-chave: teatro comunidade, hospital de custódia e tratamento psiquiátrico, práticas teatrais.

\section{ABSTRACT}

The present report exposes an internship experience held at the Hospital of Custody and Psychiatric Treatment (HCTP) of Florianópolis, in the first semester of 2019. The practice was associated with the discipline of Supervised Curricular Internship - Theater in the Community I, of the Degree in Theater from the Arts Center (CEART) of the State University of Santa Catarina (UDESC) and aims to propose experiences beyond the hospital/prison routine, cooperating with the integration between patients and future social reintegration.

Keywords: community theatre, hospital of custody and psychiatry treatment, theatrical practices.

\section{INTRODUÇÃO}

Este trabalho propõe relatar uma experiência de estágio com prática teatral no Hospital de Custódia e Tratamento Psiquiátrico (HCTP) de Santa Catarina, em Florianópolis, oriunda 
da disciplina de Estágio Curricular Supervisionado³ - Teatro na Comunidade I, ministrada pelo professor Thiago de Castro Leite, no curso de Licenciatura em Teatro do Centro de Artes (CEART) da Universidade do Estado de Santa Catarina (UDESC). O processo com os participantes, orientado pela professora Fabiana Lazzari de Oliveira, foi iniciado em abril de 2019 e realizado na estrutura de aulas semanais de teatro. Os participantes eram todos homens, visto que o hospital é apenas masculino.

As práticas teatrais foram inseridas nesse ambiente indo ao encontro das considerações de Fernando Bueno Catelan ao buscar uma "abordagem artística na educação que fortalece a emancipação dos/as educandos/as para além de uma visão tradicional escolar" (2018, p. 80).

É preciso entender brevemente como funciona o ordenamento jurídico brasileiro em relação a imputabilidade penal, ou seja, a capacidade de discernimento da pessoa que praticou um ato definido como crime, conforme o Código Penal:

É isento de pena o agente que, por doença mental ou desenvolvimento mental incompleto ou retardado, era, no momento da ação ou omissão, incapaz inteiramente de entender o caráter ilícito do fato ou de determinar-se de acordo com esse entendimento. (BRASIL, 1940, art. 26).

Assim como os menores de dezoito anos, os doentes mentais são considerados inimputáveis ou semi-imputáveis. Salvo exceções, todo indivíduo é imputável (responsável por si e seus atos). Quando inimputável, o agente é sujeito à medida de segurança ou, no caso dos menores de dezoito anos, às normas estabelecidas na legislação especial (BRASIL, 1940). Já os semi-imputáveis podem responder pelo crime com pena reduzida ou também receber uma medida de segurança, segundo Cezar Roberto Bitencourt: 
O imputável que praticar uma conduta punível sujeitar-se-á somente à pena correspondente; o inimputável, à medida de segurança, e o semi-imputável, o chamado "fronteiriço", sofrerá pena ou medida de segurança, isto é, ou uma ou outra, nunca as duas, como ocorre no sistema duplo binário (BITENCOURT, 2016, p. 863).

Sendo um híbrido entre o sistema manicomial e carcerário (COSTA, 2017; CARRARA, 2010), a memória dos hospitais de custódia, chamados inicialmente de manicômios judiciários, tem muito a dizer. Historicamente, tratando-se de "criminosos loucos", a conduta pode diferir entre países. Em alguns, há um setor para pacientes psiquiátricos dentro do próprio presídio, em outros, setores para criminosos dentro de hospitais, e os hospitais de custódia (CARRARA, 2010). A Inglaterra foi a primeira, em 1863, a pensar em um estabelecimento destinado exclusivamente aos chamados "delinquentes alienados". O Hospital de Broadmoor existe até hoje, sendo primeiramente nomeado Broadmoor Criminal Lunatic Asylum. Sua primeira paciente foi uma mulher admitida por infanticídio, descrita como "fraca mentalmente" (BRONSON, 2015). O hospital conta com um longo histórico de má conduta e abuso por parte dos funcionários, perdurando aos dias de hoje denúncias e escândalos.

No Brasil, o primeiro hospital psiquiátrico foi inaugurado em 1852, o Hospício Pedro II, sendo também o primeiro hospital psiquiátrico da América Latina (RAMOS, 2011). E, tratando-se do contexto manicomial brasileiro, imprescindível mencionar o Hospital Colônia de Barbacena, responsável pela morte de mais de 60 mil pessoas entre o início do século XX até a década de 1980 (ARBEX, 2013). Entretanto, um local específico para abrigar aos "loucos criminosos" só foi criado em 1903, com a "Seção Lombroso" no Hospital Nacional de Alienados ${ }^{4}$. O nome foi homenagem ao médico psiquiatra e antropólogo criminal italiano César Lombroso, que desenvolveu uma teoria sobre os "criminosos natos": indivíduos que, segundo ele, nasceram com uma tendência marcada para o mal (CARRARA, 2010). E, em 1921, foi

4 Antigo Hospício Pedro II (ALVES, 2010). 
constituído o primeiro manicômio judiciário do Brasil, no Rio de Janeiro (SANTOS; FARIAS, 2014).

Somente em 1971 foi inaugurado o primeiro Manicômio Judiciário Estadual de Santa Catarina denominado, em 1994, de Hospital de Custódia e Tratamento Psiquiátrico (HCTP) (SAP, 2013), local da prática de estágio aqui relatada.

\section{A PRÁTICA TEATRAL}

Para alavancar, de fato, com o projeto, mostrava-se necessário uma preparação teórica, prática e, inevitavelmente, emocional. No entanto, não havia tempo suficiente para isso. Felizmente, também não havia tempo para sentir medo e, ademais, eu contava com o auxílio dos professores. Dessa forma, o contratempo logo foi ultrapassado com um período de observação do campo de estágio e de integração com ele - obrigatório nos estágios, pontuo isso pois nada me agrada a ideia de estar "observando" alguém. Entretanto, a observação permite conhecer a turma e formular os planos de aula. Estive presente em diversas atividades no Hospital, como festas, oficinas e saraus, em que conversávamos sobre nossas vidas, gostos e rotinas. Conheci mais do hospital pela visão deles.

Nosso primeiro contato aconteceu em uma roda de poesia e música, idealizada por incríveis colegas - agora amigas e amigos. Deram-me suporte e eu me sentia acolhida por todos. Também é significativo mencionar que o primeiro homem com quem conversei, brinquei e me enturmei, veio a falecer logo após sua retomada a vida exterior. Escrevo isso com muito carinho, pensando nele.

Ocorreu algo de curioso logo após o momento de integração. Na primeira aula a maior parte dos participantes não foram os que já havia me relacionado. Percebi que, tratando-se das atividades, como em qualquer outro local, parecia haver certos padrões nos pacientes do hospital: os que gostam e participam de todas as oficinas oferecidas; outros bastante seletivos quanto as quais irão se envolver; e alguns que não costumam participar das atividades. 
Durante a construção do projeto e busca pela metodologia mais viável, considerou-se, principalmente, os diversos fatores que diferenciavam o comportamento dos participantes, pois afetariam diretamente nas propostas das aulas. Fisicamente falando, as medicações e seus efeitos colaterais, por exemplo, poderiam ser um óbice para vários jogos. Não é necessário aduzir que a vivência de cada paciente no hospital seja distinta e não se iguale apenas por serem neuroatípicos ${ }^{5}$. Pois, mesmo neuroatípicos, são vários os transtornos, níveis de escolaridade, classes sociais e delitos cometidos. Dessa forma, o que os assemelha e os une como comunidade é o estar em um hospital de custódia ${ }^{6}$ e o tratamento lá oferecido.

Tendo isso em mente, os primeiros objetivos foram concebidos; pensando-se de forma genérica, possível de abranger qualquer indivíduo, com qualquer vivência anterior, porém na situação/local em que se encontravam. O jogo parecia ser o meIhor caminho:

O jogo é democrático! Todos podem aprender jogando! O jogo estimula a vitalidade, despertando a pessoa como um todo mente e corpo, inteligência e criatividade, espontaneidade e intuição - quando todos, professor e alunos unidos estão atentos para o momento presente. (SPOLIN, 2017, p. 30).

Por essa via, foram assimilados propósitos e caminhos que possibilitaram de forma lúdica a investigação de suas estruturas musculares e sonoras, utilizando do exercício corporal como uma "reflexão física sobre si mesmo" (BOAL, 2014, p 109). Ressalta-se, entretanto, a cautela para evitar gatilhos ${ }^{7}$ ou confundir a realidade com ficção e se atentar para a ausência do cunho terapêutico. Contudo, todo cuidado é pouco e cada caso é específico. A título de exemplo, em um exercício que consistia em lançar a bola pronunciando os nomes dos colegas, um estudan-

5 Indivíduos considerados neurologicamente diferentes (ORTEGA, 2008).

6 Grifos meus.

7 Lembranças estressantes, ansiedade ou depressão podem ativar o mecanismo disfuncional de regulação das emoções (ARCOVERDE; SOARES, 2012). 
te esquizofrênico compreendeu o jogo como um ritual satânico.

\section{UM OLHAR PARA OS OBJETIVOS}

Apesar de toda ponderação durante a elaboração do projeto, muitos pontos dos objetivos idealizados no início do projeto puderam ser revistos. A começar pela expectativa de "dar voz a". As pessoas já têm voz, ninguém precisa "levar" isso a elas. O que falta, para estabelecer esse diálogo com o mundo, é a escuta. Não saberia dizer se foi por inocência, acreditando no poder da $a_{r t e}^{8}$ e na salvação do mundo pelos exercícios teatrais; ou simples egocentrismo. De todo modo, parece que, apesar desse equívoco na colocação, não foi de todo inválido, visto que o diálogo foi tópico citado pelos integrantes do grupo no questionário aplicado ao final do semestre. Quando perguntados se o teatro ajudou a lidar com os acontecimentos e com a rotina dentro do hospital, entre as respostas, estava: "sim, através da comunicação" (vide figura 1).

Outros objetivos revisados foram a exploração do espaço e da expressividade do corpo. Planejava-se alcançar a experimentação do espaço e dos potenciais do corpo por meio de exercícios com caminhadas, propícios para a conquista do objetivo por sua capacidade de diálogo entre corpo e espaço. Tais caminhadas consistem na investigação de diferentes formas de caminhar pela sala de trabalho, investigando velocidades (eram fornecidas porcentagens a partir da ideia de que $50 \%$ representava seu ritmo habitual de caminhada); testando modificar a forma de encostar o pé ao chão, deslocando-se apenas com os calcanhares, ou nas pontas dos pés, ou talvez com as partes externas ou ainda internas dos pés; vivenciando por meio da imaginação a locomoção sobre diversos pisos em variadas circunstâncias, necessitando que expressassem com seus corpos a travessia pelo chão ora inundado, ora queimando, até quem sabe uma areia movediça se transformando em um grande chiclete no sapato. Entretanto, em minha percepção, possibilida- 
des tão promissoras do exercício não foram alcançadas. Logo na primeira vez que foi proposto, um estudante disse que era justamente o que faziam o dia todo, todos os dias. E foi visível. Andavam todos iguais, de cabeça baixa, de um lado para o outro, juntos, devagar, praticamente se arrastando. Augusto Boal explica:

Entre todas as mecanizações, a maneira de andar é, talvez, a mais frequente. É verdade que temos nossa maneira individual de andar, muito particular em cada um de nós, sempre igual, quer dizer, mecanizada. Mas também é verdade que adaptamos nossa maneira de andar ao lugar onde estamos caminhando. (BOAL, 2014, p. 124).

Essa é a maneira em que pacientes psiquiátricos caminham no contexto hospitalar/carcerário? Como será que caminhavam em liberdade? Com esses questionamentos, os exercícios de caminhada me parecem ainda mais importante, uma vez que "mudar nossa maneira de andar nos faz ativar certas estruturas musculares pouco utilizadas e nos torna mais conscientes do nosso próprio corpo e de suas potencialidades" (BOAL, 2014, p. 125). Contudo, em nossas tentativas, o espaço da sala não era o mais adequado para esse exercício, tendo limitações em seu formato. Presumo que realizar os exercícios de caminhada pelo espaço no pátio, onde de fato caminham todo o dia, seja mais estimulante - a quebra da rotina pode ser poderosa! No hospital, a maior parte dos pacientes em custódia frequenta o pátio interno e externo, dependendo do dia, do paciente, da situação. Lá, ouvem música, jogam bola, pegam sol. Quando chove, não há pátio, ficando assim em seus respectivos "barracos" como esse pode acontecer sessões extras de filme e pipoca, planejadas por funcionários atenciosos para entreter os pacientes. Percebe-se que há quem goste muito dos dias chuvosos, pela possibilidade de continuar na cama descansando. Outros, como me foi dito em sala certa vez, se sentem punidos ao não poder sair de seus barracos. Dessa forma, em dias de chuva, a dinâmi-

9 "Como os detentos chamam as celas" (JOCENIR, 2011, p. 22) 
ca das aulas muda, recebendo alunos novos - que aproveitam da oportunidade para sair dos quartos e com a falta de alunos frequentes, que por muitas vezes estão dormindo.

Outras formas de experimentação das possibilidades de expressão do corpo se deram positivamente, como a dança fragmentada. Nesse exercício, partes do corpo são indicadas para serem dançadas individualmente - cabeça, perna, cotovelo, barriga, etc. Ao final, após investigação de suas partes, expande-se para uma dança que inclua todo o corpo e a festa está feita! Lembro que em uma das primeiras aulas, na conversa final, um dos participantes relatou nunca haver feito algo parecido na vida e depois perguntou para o resto da turma se também compartilhavam da mesma sensação. Foi animador vê-los descobrindo novas formas de usar o corpo e novas possibilidades de interação. Ao questionar se teatro era necessário e de que forma, um estudante retornou: "é necessário, vem buscando um espaço legal, vem abrindo a mente da rapaziada pra lugares que não o crime, mas sim um bom caminho" (vide figura 2). Além dos exercícios citados, muito trabalhamos com o uso de brincadeiras tradicionais e conhecidas, como "quem é o mestre", "passa anel" e "dança das cadeiras" (vide figuras 3, 4 e 5). Muitas delas eram solicitadas e propostas pelos participantes que, quando requisitavam um jogo, também recebiam a missão de ensiná-lo para o resto do grupo.

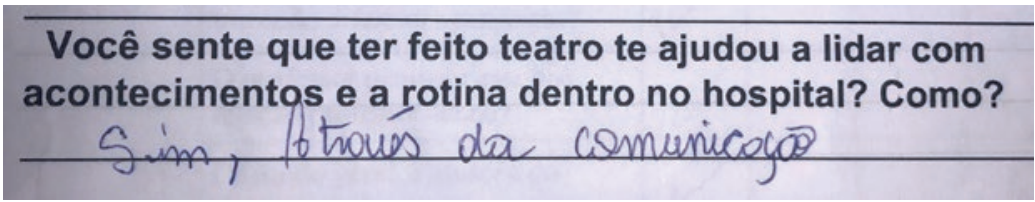

Figura 1: Questionário

Fonte: Arquivo pessoal (2019). 


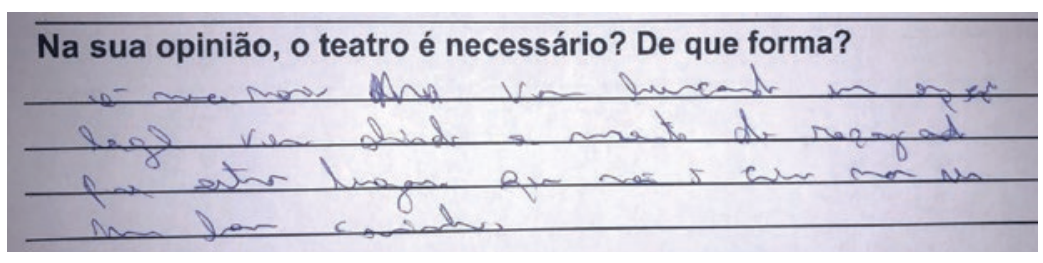

Figura 2: Questionário

Fonte: Arquivo pessoal (2019).

A introdução de um contato com o corpo do outro foi mais difícil que o esperado. Muitos se negavam a participar dos exercícios que continham muito contato físico e, quando indagados, surgia um discurso de que eram "machos" e seria "estranho". No início, quando a situação se instaurou, fiquei nervosa e cedi. Depois, mantive, disse que quem não quisesse poderia ficar de fora. Optei por não retirar o exercício do plano de aula e fazer com que assistissem aos colegas que aceitavam as propostas. Isso resultou em uma maior participação. O processo foi seguindo, com alguns mais participativos, outros menos. Dependendo do jogo, quando um não queria participar, os outros, que anteriormente também sentiam receio em participar, conversam para tentar o atrair e cativar. O mais interessante é quando o contato acontece naturalmente e eles se divertem, com cuidado e respeito. Até que a mente entra em campo e a vergonha retorna.
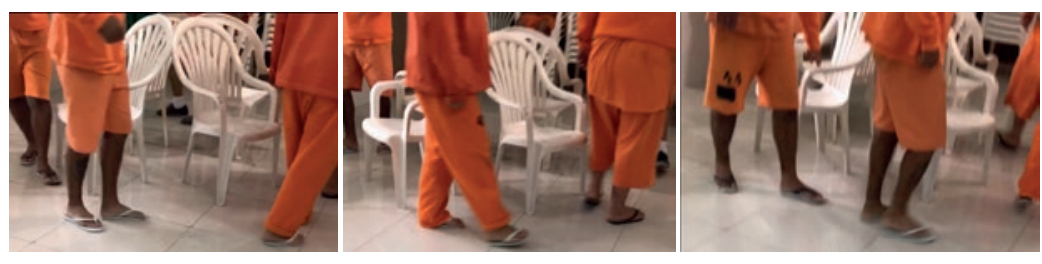

Figuras 3, 4 e 5: Atividade em sala

Fonte: Arquivo pessoal (2019). 


\section{CONSIDERAÇÕES FINAIS}

Tencionando partilhar nosso trabalho, aqui foram relatados alguns eventos desde a preparação do projeto até a análise dos ocorridos após o primeiro semestre, com intuito de exteriorizar nossa vivência, destacando a prática teatral não apenas no contexto de privação de liberdade, como também ponderando e ressaltando a neuroatípicidade dos participantes.

Observou-se, com a prática teatral, a oportunidade de integração entre os membros que, embora houvesse convivência diária no pátio, demonstraram não conhecer os demais, alguns tampouco sabiam o nome de outros companheiros. Com exercícios grupais, jogos com nomes e contações de história, foi possível perceber a formação de novas amizades para além das aulas de teatro.

Nota-se a relevância de considerar os dissímeis transtornos dos integrantes durante a estruturação das aulas e definição de metodologia, e a compreensão do nosso papel como professores - nunca terapeutas. Aponta-se a vulnerabilidade dos participantes e a preocupação necessária durante as escolhas dos jogos teatrais, com cautela para evitar gatilhos e recaídas no tratamento dos participantes.

Desde que a prática fora iniciada, cerca de oito pacientes do hospital que participaram das práticas teatrais receberam alta. Alguns foram encaminhados para residenciais terapêuticos, outros voltaram para a família e um, infelizmente, foi visto pelas ruas. A falta das suas presenças é sentida em aula, mas suas histórias e contribuições jamais serão esquecidas. É custoso não sentir saudade, contudo, o trabalho foi idealizado justamente para este momento: o de liberdade. 


\section{REFERÊNCIAS}

ALVES, Lourence Cristine. O Hospício Nacional de Alienados: Terapêutica ou higiene social?. 2010. 131 f. Dissertação (Mestrado em História das Ciências e da Saúde) - Casa de Oswaldo Cruz, Fundação Oswaldo Cruz, Rio de Janeiro, 2010. Disponível em: <https://www.arca.fiocruz.br/handle/icict/6089>. Acesso em: 14 set. 2019.

ARBEX, Daniela. Holocausto brasileiro: vida, genocídio e $60 \mathrm{mil}$ mortes no maior hospício do Brasil. [s.l.]: Geração Editorial, 2013.

ARCOVERDE, Renata Lopes; SOARES, Lara Sá Leitão de Castro. Funções neuropsicológicas associadas a condutas autolesivas: revisão integrativa de literatura. Psicol. Reflex. Crit., Porto Alegre, v. 25, n. 2, p. 293-300, 2012.

BITENCOURT, Cezar Roberto. Tratado de direito penal. [s.l.]: Saraiva, 2006.

BOAL, Augusto. Jogos Para Atores e Não Atores. 16. ed. Rio de Janeiro: Civilização Brasileira, 2014.

BRASIL. Lei n ${ }^{\circ} 2.848$, de 7 de dezembro de 1940. Código Penal. Brasília, 1940. Disponível em: <http://www.planalto.gov.br/ ccivil_03/decreto-lei/del2848compilado.htm>. Acesso em: 13 set. 2019.

BRONSON, Charles and ETHERINGTON, Lorraine. Broadmoor: my journey into hell. [s.l.]: John Blake, 2016.

CARRARA, Sérgio Luis. A História Esquecida: os Manicômios Judiciários no Brasil. Journal of Human Growth and Development, vol. 20, no. 1, p. 16, 2010.

CATELAN, Fernando Bueno. IMPROVISAÇÃO TEATRAL NA EDUCAÇÃO DE JOVENS E ADULTOS: um ato político 
emancipatório. 2018. 150 f. Dissertação. Mestrado Profissional em Artes. Instituto de Artes, Universidade Estadual Paulista "Júlio de Mesquita Filho", São Paulo, 2018.

COSTA, Maria Izabel Sanches (Ed.). Política de Saúde - Política de Segurança: Manicômio Judiciário, Entre o Hospital e a Prisão. Revista do Arquivo, São Paulo, v. 5, n. 2, p.144-160, out. 2017. Disponível em: <http://www.arquivoestado.sp.gov.br/revista_ do_arquivo/05/artigo_11.php>. Acesso em: 15 set. 2019.

JOCENIR. Diário de um detento: o livro. São Paulo: Edição Por Demanda, 2011.

ORTEGA, Francisco. O sujeito cerebral e o movimento da neurodiversidade. Mana, v. 14, n. 2, pp. 477-509, 2008. Disponível em: <http://www.scielo.br/scielo.php?script=sci_ arttext\&pid=S0104-93132008000200008>. Acesso em: 15 set. 2019.

RAMOS, Fernando A. da Cunha; GEREMIAS, Luiz. Instituto Philippe Pinel: origens históricas. 2011. Disponível em: <https:// docplayer.com.br/5842109-Instituto-philippe-pinel-origenshistoricas.html>. Acesso em: 10 set. 2019.

SANTA CATARINA. SECRETARIA DA ADMINISTRAÇÃO PENITENCIÁRIA. Hospital de Custódia Inaugura Sala de Artesanato e Academia ao Ar Livre. Disponível em: <http:// www.sap.sc.gov.br/?option=com_content\&view=article\&id=881: artigo-881\&catid=95\&ltemid=524> . Acesso em: 15 set. 2019.

SANTOS, Ana Luiza Gonçalves; FARIAS, Francisco Ramos. Criação e extinção do primeiro Manicômio Judiciário do Brasil. Revista Latinoamericana de Psicopatologia Fundamental, vol.17, n. ${ }^{\circ}$ 3, São Paulo, Sept. 2014. Disponível em: <http://www.scielo.br/ scielo.php?script=sci_arttext\&pid=S1415-47142014000300515>. Acesso em: 14 set. 2019.

SPOLIN, Viola. Jogos Teatrais na Sala de Aula: Um Manual Para o Professor. 3. ed. São Paulo: Perspectiva, 2017. 